\title{
Decision-Making Intellectual Support in the Theory of the Active Connect
}

\author{
Oleg Vyacheslavovich Lavrichenko ${ }^{1}$ \\ ${ }^{1}$ Concern, Morinformsystem-Agat, Moscow, Russian Federation \\ Correspondence: Oleg Vyacheslavovich Lavrichenko, Concern, Morinformsystem-Agat, Moscow, 111024, \\ Russian Federation. Tel: 7-903-009-6457. E-mail: lavrslava1962@mail.ru
}

Received: May 15, 2015

Accepted: August 29, 2015

Online Published: November 30, 2015

doi:10.5539/mas.v9n13p60

URL: http://dx.doi.org/10.5539/mas.v9n13p60

\begin{abstract}
Effective control of innovative resources at the enterprise requires new and creative interaction mechanisms (active connect) between decision-makers, and enterprise-wide information systems. The essence of innovation self-organizing business forming technologies is revealed for the first time in the research work, which reveals the authoring theory of active connect basics. The article proves the maximum value of Choquet integral application demand by the decision-making process modeling for the disparity elimination in innovative resources distribution. The method proposed by the author has been tested at the enterprises of the Moscow Industrial Concern "Agat".
\end{abstract}

Keywords: information systems, enterprise-wide innovation system, innovation resources, theory of the active connect, innovation self-organizing business forming technology

\section{Introduction}

Information technology (IT) and enterprise-wide innovation system (InS) play the primary role in solving the problem of the company dynamic sustainable development provision in the current world economy development, with its main trends being globalization, severe competition and limited innovation resources (InR). The results of the theory and practice analysis (Hung et al,2015) manifest that the scientific literature still lacks sufficient research in IT and InS correlation with the company competitiveness (Boss \& Chen, 2009). In 80-90-ies of the last century (Zucchi \& Edwards, 1999) the IT introduction in the innovation activity of the industrial enterprise was considered a random surge in the production process (Chau \& Ho, 2008), but today it is the only possible way or the key paradigm of its competitive development (Bodoff, 2008). This is especially relevant for large enterprises (concerns), as the larger is the company, the greater is the number of business processes involved in the profit creation. This means that IT use is really vital. IT and InS became system components of the enterprise-wide daily economic activity (Forester, 1961).

Innovation self-organizing business forming technology (ISBFT) being the endogenous basis of InS and the theory of the active connect (TAC), belongs to IT. Simple ISBFT has been considered in our previously published works (Lavrichenro, $2014 \mathrm{c}$ ). It has been identified not only as a sequence of actions for ideas implementation, but also as IT of communication between the parties of the innovation strategy of enterprise development realization process, techniques of exchange and structuring of information between them (Lavrichenko, 2014 b). It is a way of communication and formation not only of innovation strategies but also information awareness of innovation activity subjects (Lavrichenko, 2014 a). ISBFT description is possible both in the form of the reduced algorithm or elementary conceptual scheme consisting of a minimum number of elements and in the form of a detailed self-improving media object (i.e. considering the influence of anthropogenic factor). Therefore, modern ISBFT - is already a self-improving "digital organization", an interactive model of innovative development strategy implementation process (Lavrichenko, 2015). We called them ISBFT that make up the endogenous basis both of the enterprise-wide InS and TAC. Unfortunately, a unified point of view on the ISBFT category definition is still missing in the scientific literature.

The term TAC has been first introduced by the author in 2013, however, long before there was a demand for it. TAC is a comprehensive developing system of knowledge studying human economic activity, which involves extensive use of IT in the production process, distribution and consumption of public goods. Over the past 20 years emphasis was made on implementation of innovation projects in practice and in research of 
enterprise-wide innovation activity (Mital, 1997). Currently, in limited innovation resources of enterprise-wide conditions one can witness (Umble et al, 2003) a transition from a project approach in InS organization to its transformation into systematic component on the basis of wide IT application (Cui et al,2015). However, this trend in practice of industrial enterprises formulates the following problem in the modern science: if enterprise-wide InS is understood as a permanent process, then it must be based on a balanced (optimal) distribution of limited innovation resources (InR) between technological, marketing and organizational solutions within the enterprise (Nelyubin \& Podinovskiy, 2012).

The answer to the question of the structural balance of limited InR, their dynamic relationship and sequence formulated as methods, models and algorithms seems an urgent and demanded scientific knowledge on the part of decision-making group (DM group). This problem solution will allow forming prerequisites for the systematic, focused innovation development of enterprises and enhancing of their competitiveness. Thus, we can conclude that methodological issues regarding theoretical substantiation for innovation activity of the industrial enterprise by reducing the risk of inefficient use of limited InR still remain not well studied. This evidences the imbalance in the modern science and practice between the need to ensure the competitiveness of industrial enterprises and insufficient scientific and methodological apparatus. Therefore, development of modern mechanisms for intellectual support of decision-making in theTAC turns out to be a timely and urgent goal in the scientific and practical sense. All the aforementioned aspects determine the urgency of this study.

\section{Conceptual Background}

The emergence of a huge number of information models and algorithms, which are logically complete and have the property of universal acceptability markes the science of management in the $20^{\text {th }}$ century. Their use brings the results, which are quite accurately forecasted (O.Leary, 2000). The ability to use them properly, combine, and "build" more complex "constructions" of these components is simply a prerequisite for any InS development (Poston \& Grabski, 2001). ISBFT is a unit of innovation activity and an object for application of control actions on the part of DM group. Their presence or absence in InS becomes a matter of survival in the context of the increased competition among enterprises.

ISBFT is understood as a strategic integrated systematic complex of formalized regulations and procedures uniting and using as a component a well-known information and cognitive technology, wholisticaly solving the problem of interaction between information, knowledge and communication between the participants in the process of innovative strategy implementation, automating and regulating the process of technological, organizational or marketing decision-making. Action space of ISBFT is the IT and InS models and algorithms, as well as new subjects of social and economic planning.

ISBFT is an infinitely more complex phenomenon than a simple technology or algorithm. It belongs to the architectural, beyond-technology level of innovation process organization, as it systematizes, unites and controls integrated models of innovative development strategy implementation as objects involved in the enterprise-wide innovation activity. Therefore, our approach differs from those presented in other research works in placing ISBFT as an "endogenous" central part of the enterprise-wide InS. That means, although any single innovation breakthrough may seem random, ISBOT in general is developing in direct proportion to investments made in it. Investments add value to ISBFT, and vice versa. It is a vicious circle promoting the growth of a company competitiveness.

We are trying to formalize this particular idea in the present article, as innovation technologies were traditionally considered "exogenous", i.e. random and arising by themselves. The fundamental basis of ISBFT is information on how to control information, knowledge and science of other knowledge acquisition methods. The basic and the most static principle of ISBFT can be defined as an ontological "library" of models and algorithms of innovative development strategies, a system of knowledge about the development and implementation of innovation enterprise-wide system options. In this perspective ISBFT can also be called energy-informational, as its basic principle is interaction and mutual transformation of energy and information.

However, the main difference of ISBFT from simple IT is the impossibility of its mechanical transfer to another time and space. Only "peripheral", visible parts of the strategic collection of formalized policies and procedures are subject to the direct playback. But even in this case they will give positive results only in short-term projects and in the markets with weak competition. ISBFT is not only a sequence of actions for the idea implementation, but also the technology of communication between the process for its implementation participants, methodology of exchange and structuring of information between them. It is a way of communication, as well as not only of innovative strategies but also of information consciousness formation.

They can be described both as an abriged algorithm, as a simple conceptual scheme consisting of a minimum 
number of elements, and as a format of a most detailed self- improving multimedia model. It means, ISBFT is a self-improving digital organization, interactive model in the InS company structure, system creating multilevel hypertext enclosed in a clear and understandable form of interactive instruction admitting an unequivocal realization in the form of software for computers. ISBFT concept has required from us a research not only in another different line of scientific thought, but also manifested the demand for development of this line as an independent scientific knowledge area - the theory of the active connect (TAC).

\section{Area Descriptions}

ISBFT today is not just information and communication but an active connect, which is much broader in its meaning. Thus, if the term "communication" means only a line of material and information provision for the enterprise innovative activity, then the term "active connect" will mean "to connect, establish relationships, establish contacts, communicate, associate, put in a causal relationship, etc." (Skok \& Legge, 2002). The TAC is an integral, developing system of knowledge, which stipulates wide application of information and cognitive technology in innovative production, distribution and consumption of public goods, as well as information support of socio-economic processes. The novelty of the authoring approach to the active connect theory consists in the necessity to consider the transaction costs of duration and intensity of information active connect between the staff at all levels and in all ISBFT iterations. The asymmetry of information active connect between the ISBFT developers and DM group is the source of transaction costs.

Main stages of TAC development are the following: ISBFT penetration into production; mass ISBFT introduction; creation of productivity excess in innovations production area over the other branches; transition to the predominant production of information and knowledge. The TAC consists of two parts: the formal aspects (equations, logical symbols, rules, etc.) and the conceptual aspects (categories, laws, guidelines). At this stage the TAC refers to the phenomenological theories, i.e. solves the problem of structuring and primary generalization of phenomena, processes and facts relating thereto.

Fundamental characteristics of the TAC presents anthropogenic factors directly or indirectly affecting the efficiency of ISBFT processes formation and implementation. Anthropogenic factors are mediated through the human resources involved in ISBFT implementation. The result of the negative impact from the anthropogenic factors is anthropogenic successions that appear on all ISBFT iterations. For limiting of their influence it is necessary to develop an adaptive monitoring, evaluation and economic norms setting system. Anthropogenic successions characterize ISBFT entropy. The entropy characterizes the allowed chaos in the InS models and algorithms, while the negentropy characterizes their regularity. Active connect exactly has the property of negentropy, which we define as the negentropy principle of the TAC.

The basic laws of the active connect theory are the following: syntropy, exformation and passionarity. Syntropy means movement to regularity, to the ISBFT organization. For more efficient and productive operation the system totality fights the surrounding chaos by organizing and regulating the latter in order to make it act as compared to the intellectual IT, including a human being, which, according to the TAC, reveals the behavior (activity) of self-organizing systems. Syntropy processes lead to ISBFT flexibility. Exformation means intentionally deleted information. ISBFT hypertext for a person not included in its system has absolutely no meaning, because the remote context shall be unique only for the DM group. The amount of information in the conventional sign after removing part of the ISBFT context is small, but due to the exformation principle the meaning and the significance of ISBFT are transmitted accurately and clearly. Next regularity of the active connect theory is its passionarity, which means the ability to deliberate super strain, strive to purposeful activity associated with the changes in the environment surrounding ISBFT. This is a characterological dominant of any IS and InS. Passionarity impact or impulse is an impulse of ISBFT "instinct" for its self-improvement and self-organization. It is passionarity that opposes any fluctuations, which are particularly felt at the information level of ISBFT.

Thus, the tasks set for intellectual support of decision making by DM group for a balanced distribution of limited InR between enterprises in large industrial holding company (concern) is to offer innovative solutions within the scope of the TAC by applying the method of extreme values of the Choquet integral. This issue is discussed in the following sections of the present article.

\section{Materials and Methods}

So far, the bulk of the research on this issue has been devoted to solving multi -criteria versions of combinatorial optimization problems. For example, L.Galand et al (Galand et al,2010) in their article consider the problems of using the minimum spanning tree in search of the shortest path on graphs, where each edge has several weights. The resulting tree (path) is characterized by a certain vector. The authors suggest using the Choquet integral for 
aggregation of such vectors into integrated assessment for selecting the best from various options. Thus, the setting of the problem corresponds to minimizing the Choquet integral on a discrete set. The authors suggest using branches and boundaries method to reduce the amount of computations, in which the upper edge is calculated by the following property:

$$
C(v, f) \leq\langle p, f\rangle, p \in \operatorname{Core}(\bar{v})
$$

where - Choquet integral by a certain capacity $v, f=\left\{f_{1}, \ldots, f_{n}\right\}$ - weights functions, $\bar{v}$ - capacity, referred to , and $\operatorname{Core}(\bar{v})$ - the core, which (as aforementioned) is determined as fundamental probability set such as $p(A) \geq v(A) ; \forall A \in 2^{N} ; p(N)=v(N)$. The capacity is construed by the authors as non-additive measure $\mathrm{v}$ by $2^{S}$. The authors consider only the $2^{\text {nd }}$ case of alternating (submodular) capacity (i.e. $v(A \cup B)+v(A \cap B) \leq v(A)+v(B) \forall A, B \subset N)$.

Extension of this approach was proposed by D. Dubois et al (Dubois \& Fargier, 2009), who has presented a method for lower limit calculating without introducing the assumption of the capacity possessing sub-modularity and demonstrated its application to multi criteria problem concerning the shortest path on a graph. Another application of the Choquet integral in problems of combinatorial optimization was presented by M. Timonin (Timonin, 2013), who has established a goal of finding a subset of admissible set, in which the value of the Choquet integral lies in a specified area of options:

$$
C(v, f(z)) \in\left[y_{l}, y^{h}\right]
$$

The analysis of the above listed approaches to solving optimization problems of extreme values of the Choquet integral manifested that the major disadvantages are the following: neglecting of assumptions about the capacity nature; weak aggregation of arbitrary concave value functions; the impossibility of their application to the problem of robust programming for the case, where the preferences of decision-makers do not allow to uniquely determine a choice among existing options for the distribution of the enterprises (organization) InR between innovation objects (Mu et al,2015).

These shortcomings cause us to use a new method of research and approach to combinatorial optimization problems on the basis of extreme values method of the Choquet integral, since it allows overcoming the difference between individual and collective decision-making methods. It is provided in the remote form through the ISBFT application for "connectivity" in InR of enterprises and organizations control area.

The fundamental problem of the TAC is a task of the binary relations (so-called "preferences") building correct display by the selection of InR for the enterprise on a certain abstract set of possible objects of innovations among the set of elements " $R$ ". It can be formulated mathematically as the problem of homomorphism building between the structure consisting of an abstract set of "X"; a certain "number of relations" on this set, as well as a structure consisting of subsets of real numbers set "R", and familiar relations, such as "+" and others.

The problem solution is based on two main classes of theorems (Nazareth \& Choi, 2015). Assertions of representability theorems bind the certain fundamental characteristics of the initial structure with the principal opportunity of homomorphism constructing. Assertions of unicity theorems describe a number of homomorphisms connecting the structure characterized by axioms $\langle X, \geq, \ldots\rangle$ with one and the same structure $\langle R, \geq, \ldots\rangle$.

The next part of our research deals with the analysis and means of solving the task set forth in the following section of the article.

\section{Data Analysis and Results}

Balanced InR distribution in conditions of the enterprises innovation activity results uncertainty is the first class task among the decision-making problems. Thus, if the DM group preferences are in line with a number of fundamental properties (axioms), then it is possible to display these preferences using the so-called expected utility (i.e. a cognitive model). Let us introduce a formal definition of the decision-making problem under uncertainty conditions, which will be called "ensemble" $(\mathrm{S}, \mathrm{X}, \mathrm{F}, \geq)$, where $\mathrm{S}-$ is a set of InR balance conditions; X - a set of enterprises choice outcome; F - a set of function actions from $\mathrm{S}$ on $\mathrm{X}$; $\geq-$ a preference 
of the InR choice relation on $\mathrm{F}$ or on $\mathrm{X}$.

Thus, we consider the solution of the decision-making problem of the company InR distribution so, as if there has been a certain probability distribution or subjective probability, which describes how likely the occurrence of a particular outcome may be. The multi criteria problems are the second class of decision-making problems of this type. Here, the first step shall be the InR selection based on Pareto optimality, i.e. their search with non-dominated vectors of estimates. The "ensemble" $(N, X$,), where $\mathrm{N}-$ is a set of criteria for balance parameterization of InR distribution between enterprises, will be called a multi criteria decision-making problem; $X_{i}, j \in N$ - is a set of criteria values; $X=\prod X_{i}, i \in N$ - is a set of InR choice "alternatives". Thus, considering the adopted conditions and assumptions the cognitive model for the case of "at least three criteria" will have the following form:

$$
x \geq y \longleftrightarrow \sum_{i=1}^{n} v_{i}\left(x_{i}\right) \geq \sum_{i=1}^{n} v_{i}\left(y_{i}\right)
$$

The geometrical interpretation of this record means that, if two trajectories of choice preference relation inequalities have a common point, then they coincide. Herewith, each trajectory of the autonomous inequalities/preferences belongs to one of the three conditions we have adopted above. A particular case of the cognitive model is a weighted arithmetic averaging :

$$
x \geq y \longleftrightarrow \sum_{i=1}^{n} w_{i} x_{i} \geq \sum_{i=1}^{n} w_{i} y_{i}
$$

Simplicity is the undeniable advantage of the additive model (4). One may talk of the "interaction" of such criteria as complementarity, mutual substitution, correlation, etc., while dealing with multi criteria decision-making problems. At the same time, the independence axiom violations can appear in problems characterized by lack of information under uncertainty conditions - for example, in cases where possible developments are described not by one, but by several possible probability distributions. In order to resolve the problems associated with intentional conditions of independence axiom, the American team of researches (Fouchal et al, 2011) proposed weakening of the cognitive model axiomatic by replacing the independence for the so-called comonotonous independence, which has the following form:

$$
f \geq g \leftrightarrow(C) \int_{s} u(f) d v \geq(C) \int_{S} u(g) d v
$$

where $(C) \int_{s}$ and $(f) d v$ is the Choquet integral, and the discrete Choquet integral is the following:

$$
C\left(v,\left(g_{1}, \ldots, g_{n}\right)\right)=\sum_{i=1}^{n}\left(g_{i}-g_{(i-1)}\right) v\left(j \mid G(i) \geq g_{i}\right)
$$

Model (6) is a direct generalization of the cognitive model. On the one part, independence implies also co-monotonous independence, and on the other part - probability is a particular case of the additive capacity. The Choquet integral in this case coincides with the Lebesgue integral. This approach allows us to solve problems impossible to be modeled within the frames of the classical models. In turn, this expands the boundaries of decision-making problems modeling. In particular, the "evasion of uncertainty" phenomenon non-displayable in cognitive models becomes modeled with the Choquet integral. However, the recent studies manifest an imbalance between the rapidly increasing demand of the developers for automation of the Choquet integral evaluation process with the help of software on the one part and the suggestions of scientists for automation of solutions acquisition in this area.

Under these conditions, Pareto- dominance turns to be a natural criterion in multi-criteria problems. As a result of the research we have identified several methods ensuring the compliance with the principle of Paretodominance by using the Choquet integral:

1. Select Pareto-optimal variant from the "g"-set of optimal InR distribution options. Whereas $g \rightarrow C(v, f) \geq C(v, g)$, then $C(v, f), f \in X_{0}$ it is always possible to find the Pareto-optimal solution among maximizers.

2. Establish " $X_{0}$ " equal to the Pareto-optimal points set. In other words, the problem of the Choquet integral maximizing will become the task of the decision clarifying among the Pareto-optimal variants. This transition can be fulfilled relatively easily in many applied problems. For example, in a problem with a limitation on the scope of distributed $\operatorname{InR} \sum i \in N Z_{i} \leq B$ it is enough to pass on to the set $\sum i \in N Z_{i}=B$.

3. Clarify " $v$ " - the capacity of the "ensemble" variants of the InR distribution in cognitive models, when not one, but several capacities satisfy DM group preferences.

Thus, cognitive models and algorithms developed on the maximum values of the Choquet integral methodological basis are the guideline for DM group in the effective intellectual support by decision-making in 
the balanced distribution of the limited InR with extensive use of the modern IT opportunities. Presentation of our results by the example of the specific industrial enterprise, as well as their prospects in comparison with the existing state of the affairs in this knowledge area are presented in the next section of the article.

\section{Discussion}

Here is an example brought for analysis of innovation systems of several enterprises included into the "Morinformsistem-Agat" Group Companies. For the sake of conveniency we shall mark them as \#1, \#2, \#3 and \#4 using the declared indexes from the balance sheets and financial statements regarding the results of innovation activity of these enterprises.

Block of data (BD) by each enterprise contains estimations by the following parameters: (1) capital assets; (2) current assets; (3) intangible assets; (4) marketing resources; (5) administrative-infrastructural resources; (6) labor resources, - further parameters 1,2,3,4.5 and 6. Aggregate estimates by all parameters are presented in Table 1.

Table 1. Aggregate indexes of BD parameters

\begin{tabular}{|c|c|c|}
\hline Enterprises & BD 2012 (million rub.) & BD 2013 (million rub.) \\
\hline$\# 1$ & 340 & 344 \\
\hline \#2 & 357 & 349 \\
\hline \#3 & 162 & 176 \\
\hline \#4 & 77 & 86 \\
\hline Total & 936 & 955 \\
\hline
\end{tabular}

Adaptive system of managerial decisions realization at the "Agat" Group Companies is presented on the scheme (Figure 1).

The task of the limited InR of the Group Companies distribution between its four enterprises shall be considered in the following statement. Organizational system consists of one center and four enterprises. The center possesses limited innovation resources R, which may be distributed between the enterprises. It is necessary to find the mechanism of innovation resources distribution, which could maximize the value of the efficiency criterion $\mathrm{K}$. In our case there is an InR deficit.Non-inclusion of merely one InR parameter into the developed cognitive model will considerably increase the forecasting error of limited InR distribution balance at the "Agat" Group Companies between its enterprises (Figure 2).

Apart from completeness of parameters, which shall be accounted in the cognitive model of InR enterprises control, time indexes of the model are also very important for the forecasting efficiency, that is the timeliness of data coming to DM group from managers of enterprises of the Group, as well as the available latency period, which shall not exceed the planning threshold (Figure 3).

For decision-making by the DM earlier in the Group Companies we have introduced the criterion, which determines the value of the results distortion for the limited InR of the Group due to the activityes of the enterprise managers, that is - the manipulation error $(M E)$. ME is a maximum discrepancy of planning results with and without consideration of subordinate managers activity by a certain metric $L$, metric $L_{1}$ is used in the work by dafault .

In view of the above and on the basis of the cognitive model, the InR is distributed between the enterprises by the following iteration algorithm:

Step $\boldsymbol{l}_{\mathbf{1}} \cdot N_{l}=N_{l-1} \backslash K_{l-1}, K_{l}=\left\{i \in N_{l}: \tau^{i} \leq q^{i}\left(N_{l}, R_{l-1}\right)\right\}$,

Step $\boldsymbol{l}_{2} . \forall i \in K_{l} x^{i}=\tau^{i}$, If $K_{l}=\emptyset$, then the algorithm stops, and $\forall i \in N_{l} x^{i}=q^{i}\left(N_{l}, R_{l-1}\right)$.

Step $\boldsymbol{l}_{3} \cdot R_{l}=R_{l-1}-\sum_{i \in K_{l}} \tau^{i} . l=l+1$. Transition to Step $l_{1}$.

By applying iteration algorithm for each of the enterprises we received the following indexes of the parameters interrelation, which have been reflected in the Tables 2,3,4,5 by a plain font. For the purpose of the comparative evaluation of our developed methodology efficiency regarding application of maximum values of the Choquet integral the same Tables presents in a bold type the indexes of the interrelation criteria for the limited innovation resources (parameters), which were calculated in the article (Lavrichenko, 2015) on the basis of non-manipulated mechanisms of managerial decision-making application. 


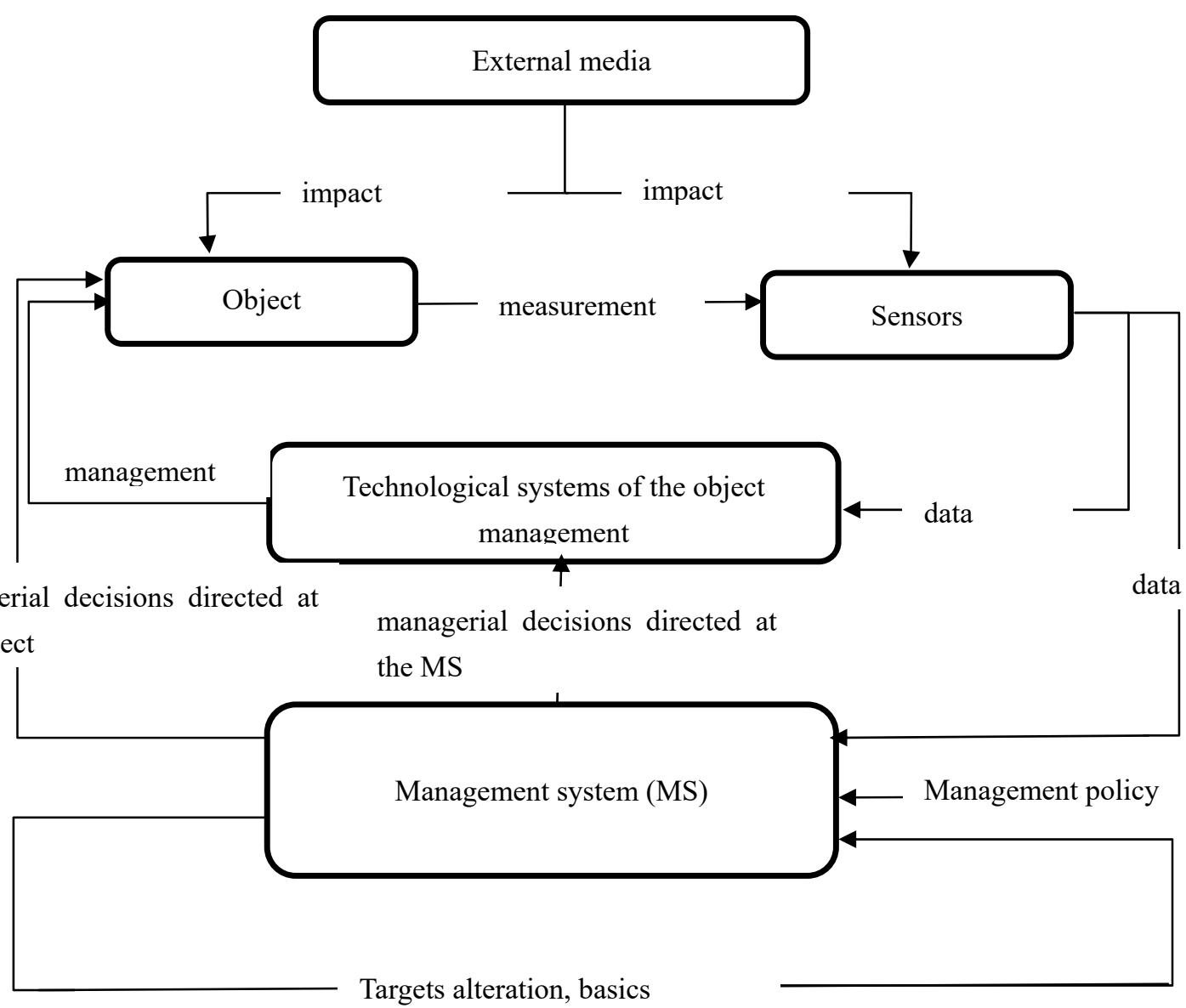

Figure 1. Adaptive system of managerial decisions formation and realization

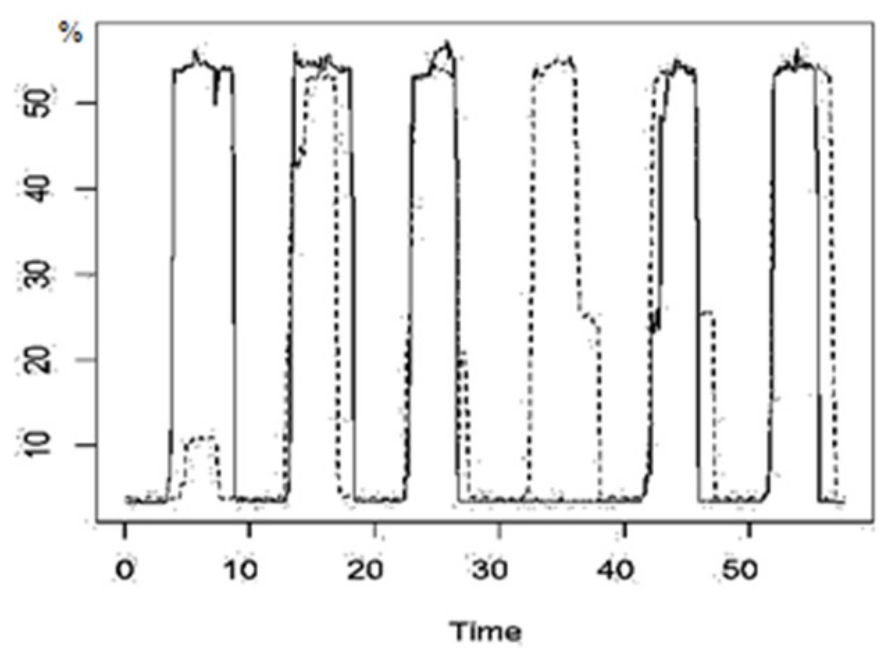

Figure 2. The example of the considerable forecast error increase by exclusion from consideration of all external parameters (solid line - real values, broken line - forecasted values) 


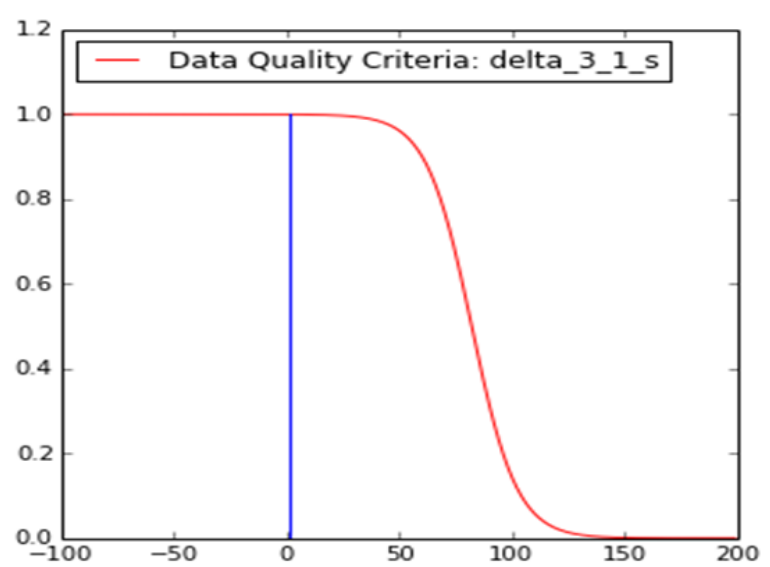

(a)

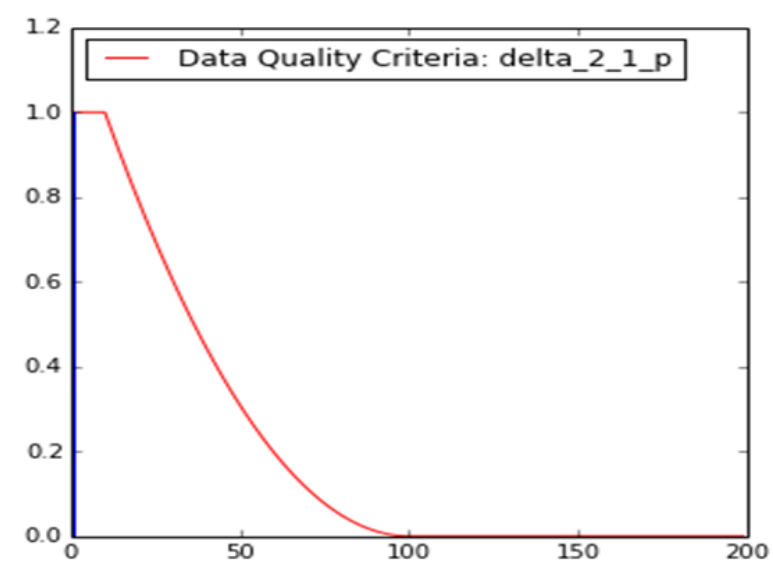

(b)

Figure 3. Indexes value: (a) forecast ing efficiency from the difference between the decision-making time by DM group and the time of the data acquisition; (b) forecasting efficiency from the available time of latency period

Table 2. Parameters interrelation indexes InR \# 1

\begin{tabular}{|c|c|c|c|c|c|c|}
\hline \multirow[b]{2}{*}{ Criteria } & \multicolumn{6}{|c|}{ INTERRELATION INDEXES } \\
\hline & 1. & 2. & 3. & 4. & 5. & 6. \\
\hline 1. & - & -0.053 & -0.200 & -0.096 & -0.100 & -0.300 \\
\hline 2. & -0.067 & - & -0.700 & 0.200 & 0.150 & 0.300 \\
\hline 3. & -0.192 & -0.067 & - & -0.600 & 0.100 & 0.119 \\
\hline 4. & -0.108 & 0.017 & -0.058 & - & 0.020 & 0.020 \\
\hline 5. & -0.100 & 0.142 & 0.100 & 0.017 & - & -0.346 \\
\hline 6. & -0.267 & -0.025 & 0.100 & 0.017 & -0.358 & - \\
\hline
\end{tabular}

Table 3. Parameters interrelation indexes InR \#2

\begin{tabular}{|c|c|c|c|c|c|c|}
\hline \multirow[b]{2}{*}{ Criteria } & \multicolumn{6}{|c|}{ INTERRELATION INDEXES } \\
\hline & 1. & 2. & 3. & 4. & 5. & 6. \\
\hline 1. & - & 0.100 & -0.040 & 0.100 & 0.135 & -0.157 \\
\hline 2. & 0.008 & - & 0.175 & -0.180 & -0.075 & 0.100 \\
\hline 3. & -0.033 & 0.175 & - & 0.175 & -0.180 & 0.050 \\
\hline 4. & 0.092 & -0.200 & -0.058 & - & 0.100 & 0.180 \\
\hline 5. & 0.133 & -0.075 & -0.033 & 0.092 & - & -0.000 \\
\hline 6. & -0.200 & 0.092 & 0.050 & 0.175 & -0.117 & - \\
\hline
\end{tabular}

Table 4. Parameters interrelation indexes InR \#3

\begin{tabular}{|c|c|c|c|c|c|c|}
\hline \multirow[b]{2}{*}{ Criteria } & \multicolumn{6}{|c|}{ INTERRELATION INDEXES } \\
\hline & 1. & 2. & 3. & 4. & 5. & 6. \\
\hline 1. & - & 0.235 & 0.065 & -0.219 & -0.120 & -0.050 \\
\hline 2. & 0.200 & - & 0.065 & -0.219 & -0.120 & -0.050 \\
\hline 3. & 0.050 & -0.050 & - & 0.035 & 0.035 & $\mathbf{0 . 0 3 5}$ \\
\hline 4. & -0.217 & -0.217 & 0.033 & - & 0.035 & 0.400 \\
\hline 5. & -0.117 & 0.117 & 0.033 & 0.033 & - & -0.300 \\
\hline 6. & -0.050 & -0.050 & 0.033 & 0.367 & 0.300 & - \\
\hline
\end{tabular}


Table 5. Parameters interrelation indexes InR \# 4

\begin{tabular}{lcccccc}
\hline Criteria & \multicolumn{7}{c}{ INTERRELATION INDEXES } \\
\cline { 2 - 7 } & 1. & 2. & 3. & 4. & 5. & 6. \\
1. & - & $\mathbf{0 . 4 0 0}$ & $\mathbf{0 . 4 0 0}$ & $\mathbf{- 0 . 4 5 0}$ & $\mathbf{- 0 . 1 0 0}$ & $\mathbf{- 0 . 1 7 0}$ \\
2. & 0.333 & - & $\mathbf{0 . 5 0 0}$ & $\mathbf{0 . 2 0 0}$ & $\mathbf{0 . 1 0 0}$ & $\mathbf{0 . 0 0 5}$ \\
3. & 0.417 & -0.583 & - & $\mathbf{0 . 1 0 0}$ & $\mathbf{0 . 0 0 0}$ & $\mathbf{0 . 1 0 0}$ \\
4. & -0.500 & -0.167 & 0.083 & - & $\mathbf{0 . 1 0 0}$ & $\mathbf{0 . 2 0 0}$ \\
5. & -0.083 & 0.083 & 0.000 & 0.083 & - & $\mathbf{- 0 . 1 0 0}$ \\
6. & -0.167 & 0.000 & 0.083 & 0.167 & 0.167 & - \\
\hline
\end{tabular}

By analyzing the data of the Tables 2,3,4,5 we can make a conclusion that our developed cognitive model if the limited InR control on the basis of the maximum values of the Choquet integral allows to significantly add the studied mechanisms of balanced InR distribution and reach optimization of the enterprise balance within the scope of its definite budget.

Comparison of the average absolute deviation figures of the cognitive model values on the basis of the non-manipulated mechanisms (NMM) from the deviation figures of the calculation model on the basis of the Choquet integral maximum values (CIM) manifested that finding of the compromise model of managerial decisions for reaching the balanced distribution of the limited IR of the Group Companies between its enterprises still remains urgent for the DM of the Group (Table 6).

Table 6. Average absolute divergence values for different models

\begin{tabular}{lcc}
\hline Model & BD 2012 & BD 2013 \\
\hline CIM & 0,0541 & 0,0518 \\
NMM & 0,0496 & 0,0501 \\
\hline
\end{tabular}

With a view to finding a compromise model, the author has developed a computer program: "The automation program of the split-level innovation systems remote control (AC InS)" (Lavrichenko, 2014 a). Its application by the DM group of the concern and by the managers of industrial enterprises allows with the help of the computer to provide effective intellectual support of decision-making for the balanced InR distribution.

The authoring computer program "AC InS", developed on the basis of our proposed cognitive model for each enterprise belonging to the Group Companies, is launching algorithms implementing the method of automatic comparison of the InR distribution balance for DM of the Group control, and providing them the results of evaluation of the forecast error in the test sample form for each model to select the most optimal variant.

Parameters of cognitive models of enterprises obtained as a result of the computer program operation are stored in the database together with the metadata parameters in the format XML (Figure 4). 


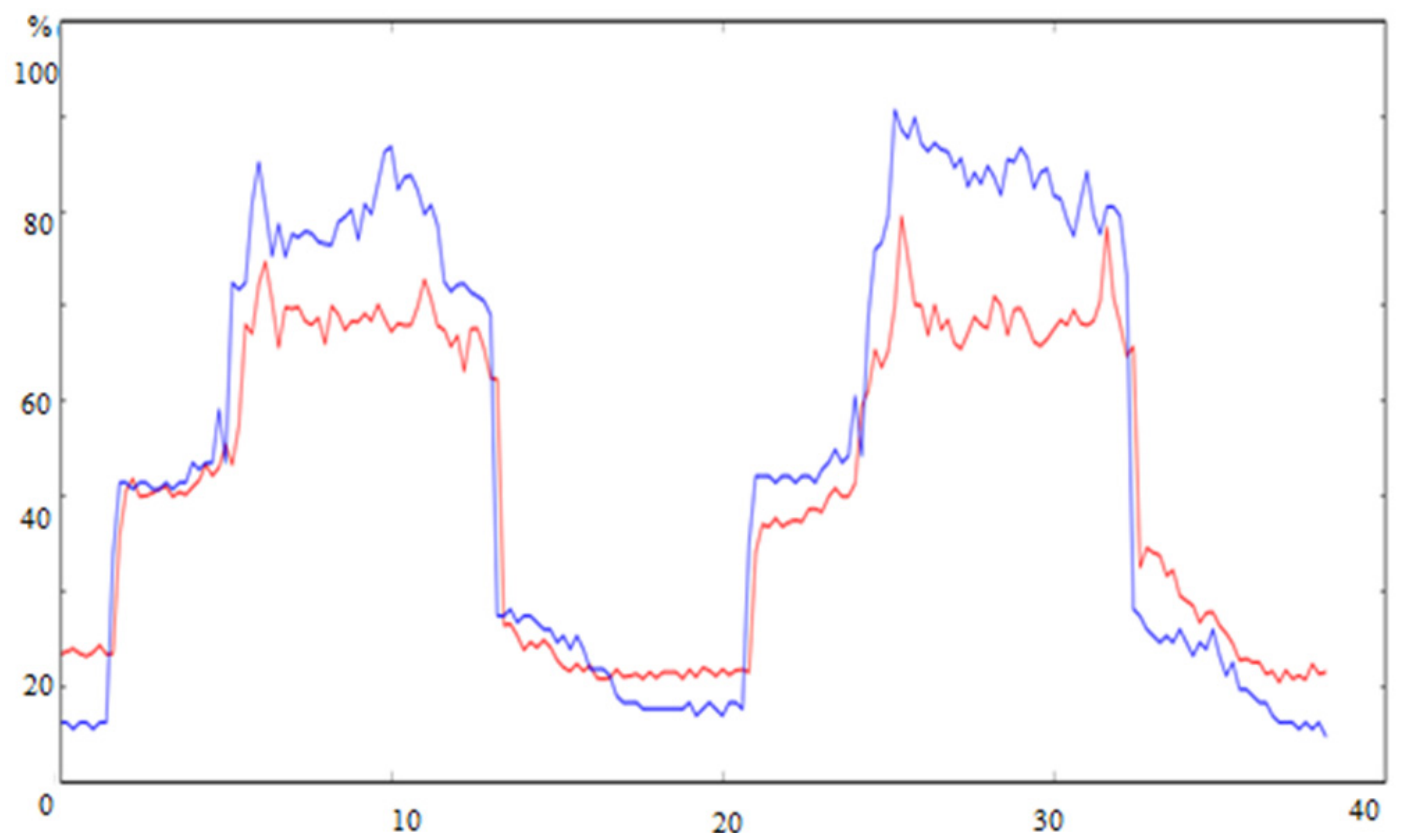

Figure 4. Example of forecasted values data visualization of the compared cognitive distribution models

Thus, upon the development of the new cognitive model it is advisable for the DM of the concern to carry out a comparison with the existing model and take a decision on the application of the best model in terms of the prediction errors assessment.

\section{Conclusions}

Summing up the present research work we can make the following conclusions:

1. Independence condition for binary relations of innovation resources and innovation objects is not fulfilled in the majority of practical tasks for the research of resources distribution balance disparity. That is the reason why the weakening of this axiom becomes the necessary condition for correct models creation in the problems of decision-making for managers of enterprises.

2. Integral Choquet application significantly broadens opportunities of decisions optimization for managers both in cases of multi criterion problems and by decision-making in conditions of ambivalence.

3. Currently, the methods of extremal values for Choquet integral search and their application in decision-making problems are not sufficiently studied, that is why the creation of more effective methodology and algorithms on the basis of Choquet integral is important both on theoretical and practical levels.

\section{References}

Bodoff, D. (2008). Test Theory for Evalution Realiability of IR Test Collections. Information Processing and Management, 44, 1117-1145. http://dx.doi.org/10.1016/j.ipm.2007.11.006

Boss, S., \& Chen, X. (2009). Quantitative models for direct marketing: A review from system perspective. European Journal of Operational Research, 195, 1-16. http://dx.doi.org/10.1016/j.ejor.2008.04.006

Chau, P. Y. K., \& Ho, C. K. Y. (2008). Developing Consumer-Based Service Brand Equity via the Internet: The Role of Personalization and Trialability. Journal of Organizational Computing and Electronic Commerce, 18, 197-223. http://dx.doi.org/10.1080/10919390802198956

Cui, T., Ye, H., Teo, H., \& Li, J. (2015). Information technology and open innovation: A strategic aligment perspective. Information \& Management, 52, 348-358. http://dx.doi.org/10.1016/j.im.2014.12.005

Dubois, D., \& Fargier, H. (2009). Capacity refinements and their application to qualitative decision evaluation. Symbolic and Quantitative to Reasoning with Uncertainty Lecture Notes in Computer Science, 5590, 311-322. http://dx.doi.org/10.1007/978-3-642-02906-6_28

Forrester, J. W. (1961). Industrial dynamics. Cambridge, MA: MIT Press. 
Fouchal, H., Gandibleux, X., \& Le, H. (2011). Preferred solutions computed with alabal setting algorihm based on Choque integral for multi-objective shortest paths.New York, N.Y.: Atheneum Publ.

Galand, L., Parny, P., \& Spanjard, O. (2010). A branch and bound Choque integral optimization in multicriteria problems.New York,N.Y.: Atheneum Publ.

Hung, W. H., McQueen, R. Y., Yen, D. C., \& Chau, P. Y. K. (2015). Measuring the aligment of websites and organizational critical activities. Technology Analysis and Strategic Management, 27, 550-568. http://dx.doi.org/10.1080/09537325.2015.1019451

Lavrichenko, O. V. (2014a). Development of sampling analysis of multidimensional structures of the innovative enterprise systems. European science, 1, 9-17.

Lavrichenko, O. V. (2014b). Development and support of a probality-sampling method of analysis of innovation systems of the Far-Eastern industrial enterprises as multidimensional structures inhomogeneous set of objects innovation. Austrian journal of technical and natural sciences, 9-10, 108-11.

Lavrichenko, O. V. (2014c). Intentionality of the theory of economics of active connect. Paradigms of knowledge, $3,22-28$.

Lavrichenko, O. V. (2015). Forming business innovative technologies are the endogenous basis of the innovation system of an industrial enterprise (2nd ed.). Vienna: "East West Association for Advanced Studies and Higher Education GMBH" Publ.

Mital, A. (1997). What role for humans in computer integrated manufacturing? International Journal of Computer Integrated Manufacturing, 10, 190-198. http://dx.doi.org/10.1080/095119297131291

Mu, E., Kirsch, L. J., Brian, S., \& Butler, B. S. (2015). The Assimilation of enterprise information system: An interptetation systems perspective. Information \& Management, 52, 359-370. http://dx.doi.org/10.1016/j.im.2015.01.004

Nazareth, D. L., \& Choi, J. (2015). A system dinamics model for information security management. Information \& Management, 52, 123-134. http://dx.doi.org/10.1016/ j.im.2014.10.009

Nelyubin, A., \& Podinovskiy, V. (2012). Algorithmic decision rule using ordinal criteria importance coefficients with a first ordinal metric scale. Comput. Math. Phys., 1, 43-59.

O.Leary, D. E. (2000). Enterprise recourse planning systems: Systems, life cycle, electronic commerce and risk. Camdridge, MA: Cambdridge Univercity Press. http://dx.doi.org/10.1017/CBO9780511805936

Poston, R., \& Grabski, S. (2001). Financial impacts on enterprise resource planning implementations. International Journal of Accounting Informatinon Systems, 2, 271-294. http://dx.doi.org/10.1016/S1467-0895(01)00024-0

Skok, W., \& Legge, M. (2002). Evaluating enterprise resource planning system using an interpretive approach. Knowledge and Process Management, 9, 72-82. http://dx.doi.org/10.1002/kpm.138

Timonin, M. (2013). Robust optimization of the Choque integral. Retrieved from http://sciencedirect.com/science/article/pii/SO165011412001856

Umble, E. J., Haft, R. R., \& Umble, M. M. (2003). Enterprise resource planning: implementation procedures and critical success factors. European Journal of Operational Research, 146, 241-257. http://dx.doi.org/10.1016/S0377-2217(02)00547-7

Zucchi, F., \& Edwards, J. S. (1999). Human resource management aspects of business process reengineering: A survey. Business Process Management Journal, 4, 325. http://dx.doi.org/10.1108/14637159910297376

\section{Copyrights}

Copyright for this article is retained by the author(s), with first publication rights granted to the journal.

This is an open-access article distributed under the terms and conditions of the Creative Commons Attribution license (http://creativecommons.org/licenses/by/3.0/). 